\title{
ANALISIS PROSEDUR PENYIANGAN BAHAN PUSTAKA PADA RUANG KOLEKSI UMUM DI UPT PERPUSTAKAAN UNIVERSITAS HALU OLEO KENDARI
}

\author{
Aswinda $^{1}$, Siti Harmin ${ }^{2}$, Muhammad Rajab ${ }^{3}$ \\ Program Studi Perpustakaan dan Ilmu Informasi Fakultas Ilmu Sosial dan Ilmu Politik Universitas Halu \\ Oleo \\ Kampus Hijau Bumi Tridharma, Anduonohu , Kec. Kambu Kota Kendari, Indonesia \\ Email: windans334@gmail.com
}

\begin{abstract}
ABSTRAK
Penelitian bertujuan untuk mengetahui prosedur penyiangan bahan pustaka pada ruang koleksi umum di UPT Perpustakaan Universitas Halu Oleo Kendari. Penelitian ini menggunakan Konsep konsep prosedur penyiangan oleh Yulia (2010: 937) dan metode penelitian yang digunakan dalam penelitian ini adalah metode penelitian deskriptif kualitatif.Teknik penentuan informan dalam penelitian ini adalah purposive samplingdenganjumlah informan sebanyak 3 orang. Teknik pengumpulan data yang digunakan dalam penelitian ini yaitu obeservasi, wawancara dan dokumentasi. Hasil penelitian ini menunjukan bahwa prosedur penyiangan bahan pustaka pada ruang koleksi umumdilakukan dengan menjadikan kondisi fisik, tingkat keterpakaian dan duplikasi sebagai acuan dalam pemilihan bahan pustaka.Pemberian cap "Dikeluarkan dari koleksi perpustakaan" sebagai bukti bahwa bahan pustaka itu sudah bukan milik perpustakaan lagi juga dilakukan serta bahan pustaka yang sudah rusak berat dan tingkat keterpakaiannya rendah dan bahan pustaka yang duplikasinya banyak nantinya tidak akan dikembalikan lagi ke rak namun akan digudangkan ataupun disumbangkan saja.Penukaran koleksi atau hibah pada bahan pustaka yang disiangi dilakukan dengan memperhatikan tingkat keterpakaian dan banyaknya eksampar pada bahan pustaka tersebut.penempatan koleksi yang sudah disiangi di gudang terlebih dahulu menarik kelengkapan koleksinya seperti kartu catalog buku yang nantinya akan dijadikan arsip bagi perpustakaan. Data 3 tahun terakhir bahan pustaka tersebut digunakan oleh pemustaka sebagai acuan dalam kegiatan penyiangan yang dilakukan serta serta penyelamatan konten isi dari bahan pustaka yang disiangi tidak dilakukan.
\end{abstract}

Kata Kunci :Analisis; Prosedur Penyiangan; Bahan Pustaka

\begin{abstract}
The purpose of this study was to see the procedure of weeding library materials in the general collection room at the Halu Oleo Kendari University Library. The study used the concept of weeding procedures by Yulia (2010: 937) and the research method used in this study was descriptive qualitative research methods. The technique of determining information in this study was purposive sampling with 3 informants. The data techniques used in this research are observation, interview and documentation. The results showed that the procedure of weeding library materials in the general collection room was carried out by making the physical condition, level of use and duplication as a reference in selecting library materials. The stamp "removed from the library collection" proves that the library material is no longer owned by the library and library materials that have been heavily damaged and have low levels of use and library materials with many duplicates will not be returned to the shelf but will be stored or donated. The exchange of collections or grants for weeded library materials is carried out by taking into account the level of use and the number of expands on these library materials. placing the weeded collection in the warehouse first, first, it will first pull the completeness of the collection, such as a book card catalog which will later be used as an archive for the library. The data for the last 3 years of library materials are used by users as a reference in weeding activities carried out and saving content from library materials that are not weeded.
\end{abstract}

Keywords: Analysis, Weeding Procedure, Library Material 


\section{PENDAHULUAN}

Perpustakaan merupakan suatu lembaga atau sarana pendukung bagi suatu organisasi. Terutama dalam suatu perguruan tinggi, karena mampu mendukung Tridharma perguruan tinggi yaitu pendidikan, penelitian, dan pengabdian masyarakat. Dalam perguruan tinggi sendiri perpustakaan mempunyai tugas untuk memenuhi seluruh kebutuhan informasi sivitas akademika dari perguruan tinggi tersebut baik untuk pendidikan dan penelitian.

Dalam perpustakaan memiliki berbagai macam koleksi diantaranya koleksi umum, koleksi khusus dan koleksi referensi. Koleksi umum merupakan koleksi yang paling banyak sekali bahan pustaka didalamnya yaitu terdiri atas buku mengenai komuputer, informasi dan referensi umum, filsafat dan fsikologi, agama, ilmu social, bahasa, sains dan matematika, teknologi, kesenian dan rekreasi, kesusastraan, sejarah dan geografi.

Kegiatan yang harus dilakukan oleh pustakawan adalah penyiangan, di perpustakaan penyiangan dilakukan terutama untuk koleksi tercetak. Penyiangan koleksi adalah proses seleksi bahan pustaka dengan cara dikeluarkan dari rak karena isinya sudah tidak relevan lagi, jumlah eksamplarnya cukup banyak, sudah ada yang lebih baru atau merupakan bahan pustaka yang termasuk ke dalam kelompok yang dilarang oleh pemerintah. Tujuan dari kegiatan penyiangan koleksi ini yaitu untuk menghemat tempat di rak. Dengan dikeluarkannya buku-buku yang sudah tidak relevan lagi karena pesatnya perkembangan ilmu pengetahuan, maka masih tersedia ruang untuk buku-buku yang lebih baru berdasarkan tahun terbit.

Sebuah perpustakaan tanpa melakukan penyiangan maka koleksinya menjadi tidak mutakhir dan sulit dimanfaatkan oleh pengguna karena koleksi tua yang tidak terpakai bercampur dengan koleksi yang mutakhir, fungsi utama perpustakaan adalah mengumpulkan dan melestarikan berbagai sumber daya pengetahuan, namun tidak mungkin juga bagi sebuah perpustakaan mengumpulkan seluruh terbitan yang ada di dunia. Penyiangan koleksi perpustakaan diatur dalam Standar Nasional Indonesia (SNI) 7330: 2009 menyatakan bahwa penyiangan koleksi adalah kegiatan mengeluarkan materi perpustakaan yang sudah tidak dipakai lagi dari koleksi.

Perpustakaan Universitas Halu Oleo Kendari adalah salah satu perpustakaan perguruan tinggi yang juga menyediakan sarana dan prasarana untuk menunjang Tri Darma perguruan tinggi.Oleh karena itu, penyiangan koleksi perpustakaan Universitas Halu Oleo Kendari dilakukan dengan tujuan untuk menghemat, meningkatkan kualitas koleksi, meningkatkan kepuasan pembaca. Dengan adanya kegiatan penyiangan yang dilakuan di perpustakaan Universitas Halu Oleo Kendari diharapkan dapat menyeleksi koleksi-koleksi yang sudah tidak terpakai lagi, koleksi yang sudah rusak dengan tujuan penyegaran terhadap koleksi perpustakaan agar koleksi perpustakaan dapat digunakan lebih akurat, relevan, up to date, menarik, serta dapat memberikan kemudahan bagi pemakai atau pustakawan dalam menggunakan koleksi, dan penyumbangan koleksi yang tidak digunakan pada perpustakaan yang lebih membutuhkan.

Oleh karena itu untuk menganalisis tindakan penyiangan tersebut apakah sudah sesuai dengan prosedur penyiangan yang ada atau tidak yang dilakukan oleh pihak UPT Perpustakaan Universitas Halu Oleo Kendari, maka perlu adanya suatu penelitian agar kasus tersebut dapat diketahui lebih jelas karna sangat jarang perpustakaan yang ingin melakukan kegiatan penyiangan karna berbagai alasan seperti adanya rasa tidak rela untuk menyingkirkan koleksi yang dimiliki.

Berdasarkan latar belakang tersebut, penulis tertarik untuk melakukan penelitian dengan mengangkat judul "Analisis Prosedur Penyiangan Bahan Pustaka Pada Ruang Koleksi Umum Di UPT Perpustakaan Universitas Halu Oleo Kendari".

Adapun tujuan dari penelitian adalah Untuk mengetahui bagaimana Prosedur Penyiangan Bahan Pustaka Pada Ruang Koleksi Umum Di UPT Perpustakaan Universitas Halu Oleo Kendari. 


\title{
2. METODE PENELITIAN
}

Dalam penelitian ini, jenis penelitian yang digunakan peneliti adalah penelitian deskriptif dengan menggunakan pendekatan kualitatif. Penelitian ini bertujuan memberikan gambaran tentang bagaimana prosedur penyiangan bahan pustaka pada ruang koleksi umum di UPT Perpustakaan Universitas Halu Oleo Kendari. Subjek penelitian dalam penelitian ini adalah 14 orang yang bertugas melakukan penyiangan bahan pustakan pada ruang koleksi umum UPT Perpustakaan Universitas Halu Oleo Kendari dan Informan pada penelitian kualitatif ini dipilih dan ditentukan dengan pertimbangan-pertimbangan tertentu yang telah ditentukan oleh peneliti. Informan tersebut adalah 3 orang pustakawan yang bertugas melakukan penyiangan bahan pustaka pada ruang koleksi umum di UPT Perpustkaan Universitas Halu Oleo Kendari. Teknik pengumpulan data yang digunakan dalam penelitian ini adalah Penelitian Lapangan. Penelitian lapangan dilakukan dengan cara observasi, wawancara dan dokumentasi. Serta Analisis data kualitatif yang dilakukan dalam penelitian ini yaitu reduksi data dan menarik kesimpulan.

\section{HASIL DAN PEMBAHASAN}

\section{Prosedur Penyiangan Bahan Pustaka Pada Ruang Koleksi Umum di UPT perpustakaan Universitas Halu Oleo Kendari}

Adapun prosedur dan tahapan penyiangan yang dilakukan oleh pihak UPT Perpustakaan Universitas Halu Oleo Kendari dalam menyiangi bahan pustaka pada ruang koleksi umum yaitu dilatar belakangi oleh kerusakan berat pada bahan pustaka sepertu buku yang halamanya sudah banyak yang hilang, buku yang dimakan rayap, buku yang isinya sudah tidak up to date lagi, serta buku yang jumlah eksamplar atau duplikatnya sudah banyak, maka langkah yang diambil yaitu dengan menyiangi koleksi tersebut. Seperti yang dikatakan oleh informan 1 yaitu sebagai berikut:

\begin{abstract}
"Penyiangan di perpustakaan universitas halu oleo dilakukan 1 kali dalam 5 tahun, itu merupakan waktu yang ideal dalam penyiangan pada bahan pustaka. Mengenai prosedurnya itu ya memang ada prosedur tertentu yang sesuai dengan ketentuan, bahan pustaka yang disiangi itu misalnya buku yang kondisinya rusak parah, buku yang isinya sudah tidak mutakhir lagi, dan juga buku yang eksamplarnya sudah banyak, yang seperti itu memang harus disiangi agar koleksi yang nantinya digunakan oleh pemustaka layak dibaca dengan isi konten yang lengkap" (Darmawati, wawancara tanggal 19 agustus 2020).
\end{abstract}

Kegiatan penyiangan biasanya dilakukan dimulai dari membentuk panitia, pembuatan proposal untuk pendanaan kegiatan kemudian melakukan pemilihan berdasarkan pedoman penyiangan. UPT Perpustakaan Universitas Halu Oleo dalam melakukan kegiatan terlebih dahulu membuat panitia dengan menentukan coordinator dan sebagainya kemudian membuat proposal kegiatan yang nantinya akan dikirim ke rektorat bagian perencanaan untuk disetujui, hal ini seperti diungkapkan oleh informan 1 yaitu sebagai berikut :

"Dalam kegiatan penyiangan ada kita buat proposal, didalamnya ada RAB (rencana anggaran biaya). Dalam kegiatan penyiangan, kegiatan perawatan itu juga dilakukan karna buku yang disiangi itu terdiri dari beberapa masalah ada yang rusak berat dan sudah tidak layak dibaca, ada yang rusak berat tetapi masih sering digunakan, ada yang rusak ringan dan sabagainya. Nah dalam kegiatan penyiangan yang masih bisa digunakan yah diperbaiki itu namanya perawatan diamana dalam perawatan membutuhkan dana juga" (Darmawati, wawancara tanggal 19 agustus 2020).

Kegiatan penyianagan di UPT Perpustakaan Universitas Halu Oleo Kendari dilakukan berdampingan dengan kegiatan perawatan, bahan pustaka yang pada saat disiangi masih banyak yang tingkat keterpakaiannya masih tinggi maka akan diperbaiki kemudian di pajang kembali dirak sedangkan bahan pustaka yang sudah jarang digunakan akan digudangkan saja dengan melalui beberapa prosedur.

Berdasarkan prosedur penyiangan koleksi perpustakaan, penulis mendapatkan hasil dari wawancara kepada infroman UPT Perpustakaan Universitas Halu Oleo Kendari sebagai berikut: 


\section{Pemilihan Koleksi}

Dalam proses pemilihan koleksi bahan pustaka yang akan disiangi juga juga sebaiknya dipilih dengan memperhatikan kriteria penyiangan koleksi seperti kondisi fisik bahan, isi, penggunaan, dan duplikasi. Proses pemilihan koleksi bahan pustaka yang akan disiangi di UPT Perpustakaan Universitas Halu Oleo Kendari dilakukan dengan menjadikan kondisi fisik, tingkat keterpakaian dan jumlah eksamplar atau duplikasi sebagai acuan dalam pemilihan bahan pustaka yang akan disiangi.

Berdasarkan hasil wawancara dengan informan diatas, hal ini memberikan gambaran bahwa proses pemilihan koleksi yang akan disiangi di UPT Perpustakaan Universitas Halu Oleo Kendari yaitu dilakukan secara teratur dimulai dari penelusuran rak berdasarkan kelas sampai dengan pencatatan bahan pustaka yang terpilih untuk disiangi dengan menjadikan kondisi fisik, tingkat keterpakaian dan jumlah eksamplar atau duplikasi sebagai acuan dalam pemilihan bahan pustaka yang akan disiangi, serta dalam proses pemilihannya menghasilkan ribuan bahan pustaka yang akan disiangi.

\section{Pendataan Koleksi}

Pendataan koleksi merupakan langkah dalam proses penyiangan koleksi, dengan mendata calon buku-buku yang akan disiangi dalam 3 tahun terakhir buku itu digunakan oleh pengguna atau pemustaka.Di UPT Perpustakaan Universitas Halu Oleo Kendari dalam proses pendataannya tidak dilakukan dengan didasarkan pada data 3 tahun terakhir bahan pustaka tersebut digunakan oleh pemustaka tetapi proses pendataan bahan pustaka yang akan disiangi berpatokan pada kondisi fisik, tingkat keterpakaian, dan duplikasi bahan pustaka tersebut. Proses pendataan bahan pustaka yang akan disiangi dilakukan secara berurutan dimulai dari kelas 000 sampai dengan kelas 999, bahan pustaka yang terpilih akan disiangi dicatat identitasnya yang terdiri dari judul buku, nama pengarang, tahun terbit, ISBN dan sebagainya.

Berdasarkan hasil wawancara dari kedua informan diatas, hal ini memberikan gambaran bahwa proses pendataan koleksi karya tulis ilmiah yang akan disiangi di UPT Perpustakaan Universitas Halu Oleo Kendari tidak dilakukan dengan didasarkan pada data 3 tahun terakhir bahan pustaka tersebut digunakan oleh pemustaka tetapi proses pendataan bahan pustaka yang akan disiangi berpatokan pada kondisi fisik, tingkat keterpakaian, dan duplikasi bahan pustaka tersebut. proses pendataan koleksi yang akan disiangi dilakukan secara berurutan dimulai dari kelas 000 sampai dengan kelas 999, bahan pustaka yang terpilih akan disiangi dicatat identitasnya, serta data tersebut nantinya akan digunakan untuk pembuatan laporan yang berisikan kesimpulan kegiatan penyiangan.

\section{Penarikan Koleksi dari Rak}

Proses penarikan koleksi dari rak dalam kegiatan penyiangan bahan pustaka yang dilakukan oleh UPT Perpustakaan Universitas Halu Oleo Kendari yaitu bahan pustaka yang sudah rusak berat dan tingkat keterpakaiannya rendah, bahan pustaka yang duplikasinya banyak nantinya tidak akan dikembalikan lagi ke rak namun akan digudangkan ataupun disumbangkan saja.

Berdasarkan hasil wawancara hal ini memberikan gambaran bahwa proses penarikan koleksi karya tulis ilmiah yang akan disiangi di UPT Perpustakaan Universitas Halu Oleo Kendari yaitu memberikan cap "Dikeluarkan dari koleksi perpustakaan" sebagai bukti bahwa bahan pustaka itu sudah bukan milik perpustakaan lagi, selanjutnya bahan pustaka yang sudah rusak berat dan tingkat keterpakaiannya rendah, bahan pustaka yang duplikasinya banyak nantinya tidak akan dikembalikan lagi ke rak namun akan digudangkan ataupun disumbangkan saja, namun penyelamatan konten isi dari bahan pustaka yang sudah tidak dapat lagi digunakan dengan cara dipdf-kan tidak dilakukan. 


\section{Penukaran Koleksi atau Hibah}

Penukaran koleksi atau hibah dilakuan apabila bahan pustaka tersebut masih dapat dipakai orang lain (terutama kopiannya masih banyak dan belum out of date isinya) maka dapat disisihkan untuk bahan penukaran atau dihadiahkan.

Hal ini sering dilakukan oleh perpustakaan apabila koleksinya terlalu banyak eksamplarnya dan masih layak untuk digunakan, sama halnya dengan UPT Perpustakaan Universitas Halu Oleo Kendari dalam melakukan kegiatan penyiangan bahan pustaka yang banyak eksamplarnya serta masih layak untuk digunakan akan disumbangkan kepada fakultas-fakultas yang membutuhkan serta sekolah-sekolah yang terkait dengan bahan pustaka tersebut.

Berdasarkan hasil wawancara hal ini memberikan gambaran bahwa proses penukaran koleksi atau hibah bahan pustaka yang akan disiangi di UPT Perpustakaan Universitas Halu Oleo Kendari yaitu dilakukan dengan memperhatikan tingkat keterpakaian dan banyaknya eksampar pada bahan pustaka tersebut.

\section{Penempatan Koleksi di Gudang}

Koleksi yang akan disiangi tidak menutup kemungkinan akan dibutuhkan kembali dan akan dicari oleh pemustaka sesekali, maka dari itu koleksi tersebut terlebih dahulu disimpan dulu di suatu ruangan atau gudang penyimpanan.

Dalam kegiatan penyiangan di UPT Perpustakaan Universitas Halu Oleo Kendari, buku yang berakhir digudangkan itu sangat sedikit, hal ini dikarnakan kegiatan penyiangan dilakukan berdampingan dengan kegiatan perawatan sehingga buku yang terpilih untuk disiangi tersebut dipisahkan berdasarkan kategori kerusakan fisik, tingkat keterpakaian dan duplikasi buku misalnya buku dengan kategori rusak ringan dan masih sering digunakan oleh pengguna maka akan diperbaiki, hal ini juga berlaku pada buku yang kondisinya rusak berat tetapi masih sering digunakan maka akan tetap diperbaiki. Berbeda dengan buku yang sudah hampir tidak pernah digunakan lagi maka akan digudangkan saja tanpa memperhatikan kondisi fisik maupun jumlah duplikasinya.

Berdasarkan hasil wawancara dengan kedua informan diatas, hal ini memberikan gambaran bahwa proses penempatan koleksi di gudang yang sudah disiangi di UPT Perpustakaan Universitas Halu Oleo Kendari yaitu ditarik kelengkapan koleksinya seperti kartu catalog buku yang nantinya akan dijadikan arsip bagi perpustakaan, Koleksi yang sudah disiangi dan tidak dapat lagi digunakan tidak langsung dimusnahkan tetapi digudangkan terlebih dahulu karna tidak menutup kemungkinan bahwa sewaktu-waktu ada pemustaka yang datang mencari koleksi tersebut, serta buku yang berakhir digudangkan itu sangat sedikit karna buku yang masih bisa digunakan akan diperbaiki kemudian dipajang dirak lagi.

Tidak dapat dipungkiri bahwa tujuan utama dari perpustakaan yaitu memenuhi kebutuhan pemustakanya, kepuasan pemustaka merupakan pencapaian dari tujuan perpustakaan itu sendiri dimulai dari kondisi fisik bahan pustaka, kelengkapan bahan pustaka serta kelengkapan isi bahan pustaka tersebut menjadi penunjang kepuasan pemustaka dalam pencarian informasinya. Di perpustakaan bahan pustaka disimpan dalam waktu yang lama yaitu tahunan hingga puluhan tahun, hal tersebut juga berlaku di UPT Perpustakaan Universitas Halu Oleo Kendari dimana terdapat banyak sekali bahan pustaka yang berumur puluhan tahun masih terpajang dirak dikarnakan memang masih digunakan oleh pemustaka. Bahan pustaka tersebut tidak selamanya selalu dalam kondisi fisik yang baik, sebagian besar bahan pustaka rusak ringan ataupun rusak berat dikarnakan berbagai macam hal misalnya bahan pustaka yang lapuk dimakan rayap, cover dan isi bahan pustaka yang terlepas akibat terlalu sering digunakan, atau bahkan isi dari bahan pustaka tersebut hilang dikarnakan tangan jahil mahasiswa yang merobek lembaran yang dibutuhkannya tersebut oleh karna itu penyiangan bahan pustaka dilakukan dengan melalui berbagai prosedur kemudian hasil dari penyiangan ini nantinya akan dipertimbangkan dimana bahan pustaka yang rusak ringan akan diperbaiki kembali kemudian yang rusak parah akan digudangkan. Menurut konsep prosedur penyiangan oleh yulia (2010 : 937) pustakawan mengadakan pemilihan bahan pustaka yang perlu dikeluarkan dari koleksi berdasarkan pedoman berikut: Pemilihan koleksi, Pendataan koleksi, Penarikan koleksi dari rak, 
Penukaran koleksi atau hibah, dan Penempatan koleksi di gudang.Konsep ini belum sepenuhnya sejalan dengan penelitian yang dilakukan dimana UPT Perpustakaan Universitas Halu Oleo Kendari tidak menjadikan data 3 tahun terakhir bahan pustaka tersebut digunakan oleh pemustaka sebagai acuan dalam kegiatan penyiangan yang dilakukan, serta penyelamatan konten isi dari bahan pustaka yang disiangi tidak dilakukan secara maksimal karna tidak dibuatkannya file pdf pada bahan pustaka tersebut.

\section{KESIMPULAN}

Berdasarkan hasil analisis data yang dilakukan dilapangan, kegiatan penyiangan bahan pustaka pada ruang koleksi umum dilakukan di UPT Perpustakaan Universitas Halu Oleo Kendari sebagian besar sudah sesuai dengan prosedur yang dikemukakan oleh Yulia (2010 : 937). Kegiatan penyiangan UPT Perpustakaan Universitas Halu Oleo Kendari dilakukan 1 kali dalam 5 tahun yang terdiri dari proses pemilihan koleksi, pendataan koleksi, penarikan koleksi dari rak, penukaran koleksi atau hibah, sampai dengan penempatan koleksi digudang.

Pemilihan bahan pustaka dilakukan dengan menjadikan kondisi fisik, tingkat keterpakaian dan duplikasi sebagai acuan dalam pemilihan bahan pustaka yang akan disiangi serta dalam pelaksanannya dilakukan secara teratur. Pemberian cap "Dikeluarkan dari koleksi perpustakaan" sebagai bukti bahwa bahan pustaka itu sudah bukan milik perpustakaan lagi juga dilakukan serta bahan pustaka yang sudah rusak berat dan tingkat keterpakaiannya rendah dan bahan pustaka yang duplikasinya banyak nantinya tidak akan dikembalikan lagi ke rak namun akan digudangkan ataupun disumbangkan saja. Penukaran koleksi atau hibah pada bahan pustaka yang disiangi dilakukan dengan memperhatikan tingkat keterpakaian dan banyaknya eksampar pada bahan pustaka tersebut. penempatan koleksi yang sudah disiangi di gudang terlebih dahulu menarik kelengkapan koleksinya seperti kartu katalog buku yang nantinya akan dijadikan arsip bagi perpustakaan, Koleksi yang sudah disiangi dan tidak dapat lagi digunakan tidak langsung dimusnahkan tetapi akan digudangkan, hal ini sesuai dengan prosedur pengiangan bahan pustaka yang di kemukakan oleh Yulia (2010 : 937).

Namun, pada proses pendataan UPT Perpustakaan Universitas Halu Oleo Kendari tidak menjadikan data 3 tahun terakhir bahan pustaka tersebut digunakan oleh pemustaka sebagai acuan dalam kegiatan penyiangan yang dilakukan, serta penyelamatan konten isi dari bahan pustaka yang disiangi tidak dilakukan secara maksimal karna tidak dibuatkannya file pdf pada bahan pustaka tersebut sehingga hal ini belum sesuai dengan prosedur pengiangan bahan pustaka yang di kemukakan oleh Yulia (2010 : 937).

\section{DAFTAR PUSTAKA}

Siregar, Ridwan. 1993. "Pengelolaan Mutu Dalam Perpustakaan Perguruan Tinggi”. Buletin Perpustakaan BKS-PTN-B Vo.IV No.1-2.

Sugiyono.2009 . "Metode Penelitian Kuantitatif, Kualitatif, dan R\&D”. Bandung : Alfabeta.

Suryabrata, Sumadi. 1983. "Metodologi Penelitian". Jakarta : Rajawali.

Winoto, Yunus. 2004. "Penyiangan (weeding) bahan pustaka : sebuah tinjauan teoritis". Jurnal info PERSADA : Media Informasi Perpustakaan Sanata Darma, Vol.2 No.2, h, 17.

Yulia, Yuyu. 1999. "Perawatan Bahan Koleksi ". Jakarta : Univerwsitas Terbuka.

Yulia, Yuyu. (2009). "Penyiangan Koleksi”.Jakarta : Universitas Terbuka.

Yulia, Yuyu dan Janti G. Sujana. 2009. " Kebijakan Pengembangan Koleksi”. Jakarta:

Perpustakaan Nasional RI.

Yulia, Yuyu dan Janti G. Sujana. 2009. "Pengembangan Koleksi”. Jakarta : Universitas Terbuka. 